\title{
Transcending Boundaries: Indian Nurses in Internal and International Migration ${ }^{1}$
}

\author{
Sreelekha Nair \\ Marie Percot
}

\section{Introduction}

Migration of women for work and economic motives has attracted serious research attention only recently. As Thapan points out, mainstream theories perceive migration as 'being mainly a male movement with women either being left behind or following their men folk as dependents', despite the almost equal number of women and men engaged in migration (2005:11). Even when women are seen as engaging in productive work outside the household after migration, they are seen as secondary earners and dependents in the processes of migration ${ }^{2}$. Yet there are remarkable number of women who migrate as single women in search of a livelihood, relying completely on their all-female networks of friends and acquaintances. Interestingly, along with the questioning of the existing construction of mainstream migration as male movement came the critiquing of migration as 'linear, one-directional, with a beginning in one culture and an end in another' (Harzig 2001:16). Migration often does not follow a clear-cut route, and step by step migration as well as return migration is part of the process of migration by populations across the globe. Literature on women and migration, of late, has stated the fact that knowledge of opportunities and constraints inform the decisions on migration of women. Family, societal and cultural considerations and economic motivations influence these decisions. 
Nurses' migration- from that of wet nurses to the nurses of the modern hospital systems- is as old as the history of humanity and has been widespread across the world. Movements by this segment of the migrant workforce have not received the necessary attention in the academic literature due to the supposed 'banality' of the whole process. However, the nature and size of the migration of nurses has changed over the last few decades. Recently, the shortage of nurses in western countries has induced greater demand for them in India, so that Indian nurses now form an important segment of the 'care sector ${ }^{3}$ '.

This paper discusses the case of Indian nurses who take up their profession as part of a family strategy, where planning for education and migration are intrinsic to the whole process. In effect, they migrate in a step-by-step phased manner: first within Indian states, mainly to metropolises, then to countries in the Persian Gulf, and further towards the West. It is not a simple, linear course of migration for them nor is it unique in any extraordinary way: yet their stories offer a terrain that is hitherto unexplored. The processes of migration start in the family milieu and involve considerations of job opportunities and information networks, working through precarious work contracts and unreliable middlemen. Meanwhile, their plans often include the life stages of marriage and motherhood. But anyhow, becoming a nurse in India today is in effect preparing to leave one's homeland, if not forever, at least for long periods of time. The question of constant mobility and negotiation of boundaries within family and the outside world are, therefore, at the heart of the matter.

It is in the context of the emerging literature that throws light on the gap between the actual experiences of women in migration and the hitherto dominant ideas on migration that this paper tries to narrate the experiences of migrant nurses from Kerala. As already mentioned, migration is a family strategy carried out by individual women, inter-connected by the structural conditions of the economy and job opportunities along with careful considerations of existing ideals of gender behaviour and class status. Family plays an important role, directly and indirectly, in every stage of migration and this aspect is discussed from their first migration to schools of nursing to migration to western countries. Their movement is fluid and an attempt to understand that requires a nuanced approach and analysis. 
Migration in their cases is a break neither with the past nor with the place of origin. The social and political context of the space left behind and entered is not lost on migrant women. They relate and respond to these contexts which form the backgrounds to the subtle assertions of their multiple identities.

Running through this paper are the diverse levels of interactions of the women migrants with different local populations. This paper presents the perceptions of the nurses regarding their social interaction with them as well as the migrant population from Kerala. Different milieus of interface with the local population are depicted - in Delhi, the Persian Gulf - and also at the level of their desire which ultimately may be differently perceived after they live through social life in western countries. They make sense of the new, unfamiliar locales through their exchanges with the inhabitants of these new spaces. It is a relation of interdependence, yet the legal rights of the citizens and customary privileges of the original residents of the locality dominate the discourse on the relationship between the locals and the migrants.

\section{The Field: as 'one's own' culture and as an 'other' culture}

This article is based on multi-sited fieldwork experiences of two researchers in their separate studies on Malayali ${ }^{4}$ nurses in the Gulf and in Delhi ${ }^{5}$. The first of the two studies in this paper was conducted on Malayali nurses, through fieldwork in Kerala and Mumbai in 2002, 2003 and 2004 and six weeks in Oman and the United Arab Emirates in 2003. Approximately 6 weeks were spent in Muscat (Oman) and the same time in UAE where all the emirates were visited but interviews were mostly in Dubaï/ Sharjah and Abu Dhabi. Nearly 300 nurses and nursing students aged between 26 and 55 (most of them were between 26 and 40 years old and married) were contacted. Close to 200 nurses who emigrated to the Gulf, about 60 exemigrants (return migrants) living for some time now in Kerala and as many nursing students of Kerala and Mumbai were contacted. 72 nurses were individually interviewed and, in other cases, group discussions of five nurses in each group were conducted. Discussion with 12 non-Indian supervisor

generals in the Emirates and Oman, 10 supervisor-generals and 15 heads of 
nursing schools or colleges in Kerala and Mumbai were part of the fieldwork carried out by M. Percot. She stayed with seventeen families of the nurses whom she met during the interviews, for a period of about two to six days each.

The second study was on Malayali nurses working in the hospitals of Delhi. In-depth interviews, apart from using structured questionnaires, with 150 Malayali staff nurses, aged between 22 and 50 years, working in Delhi hospitals for the study titled 'Gender, Status of Profession and Migration: A Study of Nurses from Kerala in Delhi' were carried out during 2004-2005. Eighty per cent of the respondents in this study are unmarried and the rest are married. Apart from going for participant observation in hospitals of Delhi, ranging from small nursing homes with 15 beds to middle level hospitals with 150 beds and super speciality hospitals with 500 beds, interviews with doctors, hospital administrators and leaders of nurses' union and professional association were also conducted. It is important to indicate at the outset that the majority of Indian nurses come from the state of Kerala and 90 per cent of the Indian nurses working in Gulf countries are Keralites. This was also the condition in Delhi hospitals which were visited for the fieldwork in this study. The field, thus, was spread over several geographical areas. Opening up of labour markets for nurses have altered its nature and broadened the number of people who enter the profession of nursing. Choice of nursing is influenced by the opportunities of employment across the world and offers a vast field for anthropologists and sociologists who are interested in looking at women, work and migration.

The narrative in this paper is the outcome of anthropological and sociological understandings of women's lives by two researchers spatially inhabiting two worlds connected by feminist standpoints. One of us looks at an 'other' culture whereas in the case of the second researcher her 'subjects' speak the same language and share the same cultural space and background. And to that extent in the second case one feels that 'one is among one's own' to borrow from Maitrayee Chaudhuri ${ }^{6}$ and yet is not quite there to understand the intricacies of 'their lives'. Changes in the labour movements and globalisation processes have altered notions of the fields of social science research. The field is not located at just one site but is spread across national boundaries, geographical areas and cultures and hence even 'among one's 
own' one feels quite like an 'other', at least for moments. Though it does not shift the direction of the much debated 'gaze', it is brought within the realm of awareness of the anthropologists and the 'subjects'. Combining the 'objectivity' that is supposed to come with distance and the 'subjective' interpretation and understanding through experiences and participation in the same culture has helped rethink the incompleteness of 'the reality' studied by us and the mode of its presentation. It is also found to be important to keep the voices of the researched and that of the researchers distinct and yet present both smoothly to the readers.

M.N. Srinivas points out, in the context of Brahmins of the College Road and the Kurubas in the nearby colony in Mysore, that the latter were 'the other' to the Brahmins but not totally so (italics in original). "Both inhabited the same cultural universe, though perhaps, to put it very roughly, different segments of it. The situation is best described by terming the shepherds as the 'self-in-the-other' of the Brahmins and vice versa" (Srinivas 1996:656) in the context of his finding that there were significant differences in the realm of culture between the two communities; it is better not to mention that different Brahmins of the same area spoke different languages. Yet commonalities existed as far as institutions, values and beliefs were concerned. Of course there were many commonalities and yet they were not the same and looking at the 'self' with the anthropologists' eyes also helped realise this fact. This discussion brought forth the dilemmas of the authors regarding their own understanding and negotiation of differences and commonalities with the nurses whom they were studying.

For the 'outsider' researcher this study was carried out in an 'other culture' going by the traditional Anthropological understanding. This collaborative work provided the opportunity to reflect on the proverbial anthropological concern on what is more difficult- studying 'one's own' society or 'another' society. We thought that both bring with them difficulties of their own kind. It opened up discussions on how 'insider' researcher is viewed by the 'subjects' and responded to and in what ways the responses to the same questions were shaped by the status of the 'outsider' researcher. The 'subjects of the study place the 'insider' within their own understanding of their society during the interviews by asking questions on the 'private' aspects that are not very evident to them. This is a clear role 
reversal and the researcher here has to be careful that these answers do not structure their responses while trying to make it clear that the researcher is not above such 'questioning' and 'subject-hood' that they go through. Through this collaborative work we could look at and discuss some of our dilemmas in fieldwork and could understand the difference in 'positionality' between the researcher and the researched and how the difference in the perception of one as 'insider or outsider' influences this aspect as well. Nevertheless there is no doubt that the field is changed in its profile and scope by the ongoing processes of globalisation and largely liberalised labour markets. It is interesting that one can travel through the world and study the same question of migration among nurses from Kerala.

\section{Origin and Social Context of Nursing in Kerala}

A nuanced analysis of structural and other settings can explain Kerala women's preponderance in the nursing profession in India. Among Malayali nurses close to 90 per cent are Christians. Stigma against nursing (due to the fear of impurity produced through contact with patients, body fluids and sick and diseased bodies) explained, without doubt, the unwillingness of higher caste Hindus to enter the profession (For a detailed discussion on stigma and status of nursing, please see Occasional paper no. 45, CWDS). Despite the taboo on 'untouchables' practising nursing, in many places traditional dais (midwives) were from the 'lower' castes.

There are more complex issues involved in the practical participation of women from various sections of society. The resistance of Hindus and Muslims against women working outside the home is higher, compared to Christians in Kerala, and this factor definitely plays a role in this specialisation, just like the higher level of educational and professional training among Christian women did (Percot and Rajan 2007). It is also important historically that the influence of the missions in shaping modern Indian nursing was very substantial and nurse leadership certainly recruited Indians of their own faith and modelled them after western images. A numerical minority, yet socially and educationally remarkably powerful, Christians of Kerala - close to 20 per cent of the population - emerged not unexpectedly deserving candidates for the profession. However, in the 
Indian context the nursing profession was devalued for a long time (Mohan 1985; Aravamudan 1975).

Stereotypical images of Keralite nurses as coming from very poor families who have no other source of livelihood and survival exist in various parts of India and this has something to do with the earlier recruitment of large numbers of destitute women as nurses. This prevailing image of nurses ignores the fact that it is necessary to have a minimum of secondary school education apart from having at least three years of training ${ }^{7}$ in English medium in nursing and midwifery to be qualified as nurse. Indeed nurses from Kerala, it is found, belong to rather homogeneous social backgrounds. This paper finds that nurses from Kerala who are in India or in the Gulf are from families with 2 to 3 acres of cultivated land or small business of some kind, generally also with contributions by one or two agricultural labourers within the family. Apart from farming, fathers in these families work, in many cases, as part-time workers with modest qualifications. Mothers almost always are described as housewives and in a few cases mothers are schoolteachers. The family houses of the nurses and nursing students are that of the typical rural lower middleclass houses, equipped with refrigerator, television, video recorder and rooms arranged in a style close to western. Respondents in our study are clearly the first generation beneficiaries in their families who are in a position to realise their parents' dream of a better and improved standard of life by availing the opportunity of migration. Today attractive migration opportunities are also strategies of climbing the social ladder that families consciously aim for.

Nevertheless, financial investments for the education of children involve heavy expenditure and often families have to resort to bank loans. In the case of training of nurses in particular, most people till 20 years ago used to go to government schools which involved very little expenditure (which could be managed within the limited income). However due to the large number of candidates, the majority today has to look towards private schools which have mushroomed everywhere, that are believed to help in the highly competitive professional scene. That is the way parents have been investing in their children's future migration for the last 15 or 20 years. They expect a part of the nurses' income to come back to them after their migration and more importantly think of possibilities of smaller 
amounts as dowry to be given in the event of marriage of such daughters. Also important are the considerations of the ability of the nurses to help the migration of their spouse and even other members of both their family and that of the in-laws. This is found in the study of Sheba George among the migrant Keralite nurses working in the U.S. (George 2000). That is why, in spite of the diminutive status associated with nursing in the beginning, young Hindu girls (including the so called higher castes) and Muslim girls have started to choose nursing with the same objective of emigration as their fellow Christian girls.

\section{Migration: A Family Strategy}

Migration is interlinked with the educational choice of nursing in the cases of the women in the study. This section discusses various stages in the migration of nurses from home to nursing schools and colleges for training, to hospitals in Delhi for work and then to the Persian Gulf. The complexity of the process is illustrated by the various forms of migration and return migration they undertake as narrated in the section on the decisions to look for greener pastures in the western hemisphere. The centre-stage that family occupies in the decision and processes of migration, all-female networks and interaction of the migrant women with the local population are points that emerge as important in the following sections.

\section{i. The First Migration}

First departure of the young girls from their homes is, very often, as candidates of nursing to the nursing schools. They are selected for this course on obtaining Higher Secondary School Leaving Certificate. In terms of demand, government nursing schools in Kerala are the most reputed, then come the private schools which are not so prestigious and sometimes not recognised by the state. Social reputation goes a long way in the affirmation of their quality and standard. In effect, personal merit is not absent in the selection of students; nevertheless those who pass certificate from reputed private high schools (in particular those with a Christian management) certainly have better chances of getting selected by prestigious nursing 
schools. The high level of competition prevalent in Kerala prompts the majority of candidates to apply for schools faraway from their homes. There again a hierarchy of nursing schools exists: government/public schools of Delhi and Mumbai attached to big hospitals are seen as being better for a good professional future than the small schools in Andhra Pradesh and Karnataka, for instance. Usually young candidates apply to several schools at the same time and the choice is generally based on four criteria: the reputation of the school, the possible chaperoning by family members there, the cost of training and finally the possibility of staying with friends from their high schools or places of origin.

In most cases, the young recruits leave their families to live in the hostels of the nursing schools inside and outside Kerala. This separation from their parents is the first personal experience of that kind and is enjoyable for them. Almost all the nurses and students met by the researchers express their pleasure in staying with girls of the same age, of making good friends; they also speak of the happy occasions of shared meals and evenings in the hostel rooms. These aspects of their lives dominate their accounts in spite of the fact that they are subjected to a lot of restrictive rules and strict schedules, control on their movements outside hostels, and other restrictions (such as men visitors not being permitted inside the hostels and so on). But the above activities in groups offer fresh air to their lives that are also the first break from their previous family lives and village environment. There are numerous anecdotes and stories on the small liberties and freedoms, of which the following are illustrations:

"The first thing I did after arriving in the school was to buy high heeled foot wear along with some bottles of nail polish and some popular cinema magazines. It was not because I had bad ideas, but it was the first time that I could do something that I really personally wished" (Shobha, 22 years).

"At home, I am the eldest one. So, in addition to my studies, I always had something to do, like cooking or taking care of the little ones. I had no time at all for myself. Here [in the nursing school], I have time just for myself, even if we have 
to work hard. We listen to music, I can discuss things with my friends and we laugh a lot. I have pen friends in different states to whom I write long letters ... Sometimes I miss my family, but I feel more happy here" (Bindu, 19 years).

Their immediate involvement in professional life through the trainings in the hospitals during the first year of their studies is a significant experience for their entry into responsible adult life:

"Very quickly, we have responsibilities. We have to be careful with suffering people. There are not only the examination marks as in other studies, there is all the part we do in the hospital where we have no right to do anything wrong" (Letty, 21 years).

Student life, without doubt, is the period characterised by the development of individual aspirations and life plans of these young women. They, for the first time, try their abilities of living life without the parents' constant guardianship and supervision.

At the end of the three years of training, very few of them return to stay with their families. In effect, their engagement with the nursing school continues even after the training period because generally there is a contract to work in the hospital attached to the nursing school for one or two years (this compensates to some extent for the shortage in the supply of nurses in local hospitals due to the mass migration of nurses to the West or Gulf). Though there is widespread unemployment among the educated in the state of Kerala, a nurse generally finds it easy to get a job there. However, salary levels are very low (sometimes not more than Rs. 1000/- at the start) and service conditions are also very difficult. So these nurses look for jobs elsewhere in India in the initial months after their training and they prefer hospitals in the metropolises. They want more income, they admit, but they also look for other things like chances of improvement in their professional and personal lives that finally attract them to big cities. 


\section{ii. Internal Migration for Work}

Delhi and Mumbai seem to be very attractive for the nurses who start their career. They move to these cities through their networks of friends and relatives. These are almost always exclusively female, informal networks that are formed during their studies. There are no advertisements for these jobs or recruiting agencies, except in a few cases. As a rule, fellow nurses act as intermediaries between the recruiters and the recruits. Old friends from the schools and places of origin who are already working in the city often act as intermediaries. Sometimes young nurses looking for jobs make contacts after reaching the city. There are also illustrations of situations when Keralite nurses who did not know each other helped in getting jobs on the basis of professional and ethnic-linguistic solidarity. Among other such cases, one sees older nurses helping the young nurse looking for a job by introducing her to the superiors of the hospital, giving a guarantee for the professional abilities of the new girl. There is hardly any lack of opportunity of employment for a trained nurse in India and the strategy of choosing nursing is fruitful in securing a job and an income. Most often they move to other cities like Delhi without an assured work in hand, only with the certainty of job possibilities in those cities. It is here that friends from schools, some relatives or neighbours of the family back in Kerala who can accommodate them for the first few months in the new city, play a crucial role. The existence of a vast Keralite population in Delhi and Mumbai suitably facilitates this purpose.

Just as female networks decide in which direction they are headed for work, their decisions to stay in certain localities or neighbourhoods in Delhi are also determined by their networks. These contacts and the active networks with fellow nurses reassure them to take the step, without too much anxiety, to migrate and confront the unknown - in terms of the new language, culture of the big city and local population. It has been noted in earlier studies on the same subject that wherever they go, to study or work, nurses live among other Keralites, be it in an Indian city or in the Gulf for instance (Percot 2005). In the case of Delhi, the social life of the young nurses in Delhi is limited almost exclusively to those from Kerala, interactions with 'others' (non-Malayalis) being limited to active professional 
relations with doctors and patients. Thus these women migrants essentially have a social life of their own - often an all women one at that. They go out to shop and to the cinema, especially the Malayalam movies that are run once a week in selected theatres and visit friends who are in other parts of Delhi. They also get together as members of the cultural and ethnic community of Kerala on various occasions. Thus they meet in the nearby church for a service in Malayalam on Sunday mornings at 7.30 or in the celebration of the annual harvest festival of Onam where all Malayalis regardless of their religion and faith - join hands to celebrate. Nurses, thus, though physically far away from Kerala, remain part of a 'greater' Kerala which extends well beyond the geographical state. These identifications are often carried on subconsciously vis-a-vis the local population of North India which never fails to mark them out as 'South Indians' who are often stereotyped into clichéd descriptions like 'small in size and dark in complexion, with long, black and curly hair', speaking a language that is incomprehensible and so on. The local population, by and large, seems to be at a loss to comprehend the massive flow of these frail looking single women migrants looking for work and judge them as women of a dubious character. Identity politics within the migrant community in Delhi also often revolves around the patrifocal nature of gender relations as exists within the traditional and restrictive social space of Kerala.

Nurses, on the other hand, resort to subtle assertions of their identity, affirmation of their ethnic and linguistic distinctiveness and recreate the cultural context which they left behind in Kerala. It was observed during the course of the interviews that the Malayali nurses do not pose any legal problems in their movement across India, do not enter into aggressive pursuits even in their professional lives made possible by the availability of a lot of nursing jobs, but rather encounter their own 'alien status' constantly in the new space as migrants. For example, when they arrive in Delhi, their lack of fluency in Hindi, the local language, is clearly pointed out by doctors and patients and they are, definitely, at a disadvantage. Unlike in the countries of the Gulf, patients are attended to in the local language and this sharply distinguishes Malayali migrant nurses from others. Further enquiries reveal interesting aspects in relation to this: 
"They [the Hindi speaking locals] consider us as poor girls who have no means to survive back home... They look upon us in a bad way, but as we stay among Malayalis only, this is not really important. But I must say that they are not all the same. That is the case for those who are uneducated and are not used to seeing women going outside and work ... The worst case is that of patients who are rich but without any education. They think that because they pay us, we are like their slaves" (Suma, 27 years).

At the beginning, I was even afraid to go shopping by myself. I was afraid because of the poor Hindi I was speaking. I always had to ask for help from my roommate" (Leela, 32 years).

"My colleagues, in the hospital, helped me a lot. They taught me the words, helped me to repeat some sentences. If I wasn't able to understand a patient, they would come ... After one year, I was able to manage very well by myself. When you have to speak everyday, it comes quickly" (Jane, 25 years).

Thus the dominance of Kerala women in the nursing profession does help the young migrants in facing the difficulties in an unknown place. In that sense, their solidarity is remarkable and serves a purpose. Even though they do not aim at a collective action based on their ethnic status, their networking based on individual relations without any attempt otherwise to form any professional association of migrant nurses is worth serious research attention. There are not many organisational activities among the migrant nurses, particularly for effective bargaining and unionisation. Even though they come from a state which is known for high levels of political participation among the people and trade unionism, which has been illustrated vividly in the literature on Kerala (for example Jeffrey 1992), nurses come out with role strain explanations regarding their reluctance for organisational activities. Being a women-majority profession, their 
explanations revolve around the double burden of women - at home as wives and mothers and work, resulting in a time constraint for engaging in public activities. There is also almost a lack of faith in any benefits that come as a result of agitations that are held publicly. Nevertheless the root of the problem seems to lie in their individualistic problem solving approach in their careers. More importantly, in the case of most young nurses, Indian hospitals are just one 'stop-over' before their migration to farther destinations and just one episode in the whole chronicle of migration.

This decision to migrate is part of their plan from the beginning. Thus the nurses interviewed in Delhi who have migrated from Kerala explain the choices of their profession not really in terms of choosing a vocation, as the general understanding of nursing was initially, but the need to have an assured employment at the end of the studies. Once one has a nursing diploma, one is able to get away from the high unemployment situation in Kerala:

"We all know that there are no jobs in Kerala. Anyone who comes across us on the road has a B.A. or M. A. degree and is still looking for a job..." (Bindu, 26 years).

Then the possibilities of working outside the state appear more in control:

“And being from a family which has just enough (resources) to survive, it is necessary to stand on one's feet and earn one's livelihood. ... Doing any of those general courses like B.A. or B.Com does not help because you do not get a job in Kerala or elsewhere if you do not have political patronage. You also have to spend money for your studies. So I thought about nursing... The investment needed is affordable and if one is willing to migrate to other states one surely will get a job. There is no hospital in any part of the world where there is no Malayali nurse. As such Malayalis are everywhere in the world and also Malayali nurses." (Sindhu, 34 years) ${ }^{8}$. 
They also talk of gaining a good amount of independence in Delhi, a social space away from the immediate concerns of parental control, and chaperoning by neighbours and relatives.

"In Kerala without someone - brother or father or at least mother, I could not go anywhere. But here I go alone to the market, to buy vegetables, other food items and clothes. I also go with my friends to meet other friends working in other hospitals. Sometimes I come alone at 8 or even 9'clock at night. Nothing happens to me. But if I did that in Kerala there would be a scandal. Neighbours would talk badly of my character...it does not matter whether I am good or bad. I prefer to stay here than staying at home." (Raji, 23 years).

"My Papa is so strict that I feel like saying that I would have stayed in Kerala if he was not there. He never used to allow me even to meet my friends... and even to visit the neighbours he would ask my mother to accompany me..."

(Shijy, 23 years).

Interventions by the family govern the social relationships of the young nurse and moreover, it is a family strategy to encourage the girls to join the nursing profession. Nevertheless, eventually the economic and relative social freedom they gain lead to a state of dissatisfaction, if not absolute rejection, of the social and familial norms of control. This often leads to finding ways to squeeze through the system, not necessarily fighting it openly. However, the comparatively self-regulating and relatively autonomous social space in Delhi does bring with it difficult service conditions in the hospitals which, they say, are better anyway than those in Kerala. Very poor nurse-patients ratio, their position way down in the hospital hierarchy in comparison to their importance in patients' care, low salary even when it is better than that of hospitals in Kerala and sometimes administrative work including attending phone calls and accounting make nurses and nursing look unskilled in this context. Apart from all these, there are hospitals which do not respect the terms and conditions of the 
initial contract of employment with nurses. Many of them pay salaries less than the minimum wage allowed by legislation and many a time the actual amount paid and the amount shown in the official accounts are different. Even worse, hospitals can ask a nurse to leave without even serving a notice though this happens quite rarely. Maternity benefits and leave are not given in many hospitals and being pregnant means termination of service in many private hospitals because there is no provision for any such breaks. Thus the life and work in Delhi hospitals are not seen as the 'best option'.

Two years of experience as a staff nurse is the minimum required to apply for a nursing job in the Persian Gulf countries. If the hospitals in which they worked in India have a good reputation, there are better chances of working in better hospitals in the Gulf. By the end of the first few years they spent in Delhi, they gain the experience they needed along with the professional confidence. A few other factors add to their self-assurance: they have managed their lives alone - away from the protection of family members and elders, they proved capable of learning a new language and managing a new environment and they now have emerged successfully in an all-female network. Nevertheless, they also cannot put off their marriages for much longer. And all the ambitions apart, they also have to save for their marriage - a handsome dowry, with a sense of exigency, for a good marriage alliance. The chance of migration and saving more money at a later date increasingly make them spend more on migration and defer their savings for dowry. They consider the two options open to them: migration to any of the Gulf countries or even better, to the western, mainly Anglophone countries. For the second option, more preparation is needed in terms of a long waiting period and financial investment, especially for appearing and getting through examinations like IELTS and CGFNS ${ }^{9}$. Migration to the Gulf in comparison is less costly and simpler.

Thus working in Delhi and Mumbai hospitals acts as an added asset and facilitates the passage of migration to foreign hospitals. Many private agencies are active in the process of direct recruitment of nurses from Kerala to the Gulf. Ordinarily nurses have to pay a commission equivalent to three months' salary of their hospital in the Gulf for a placement through them. Though these agencies have spread their operations even to remote villages, being in a big city exposes them to well-established agents who clinch all 
the contracts with the best hospitals. There are also direct recruitment drives in big cities by the employers from the Gulf through tests and interviews supervised by their representatives. This is the most attractive option as there are no middlemen and candidates do not have to pay any fee. Most often government hospitals resort to this kind of recruitment and significantly these hospitals offer the best terms and conditions of work, along with a guarantee of employment on reaching the Gulf. Nurses often speak of these mass recruitment drives and about the aeroplanes leaving for one country or the other and also about aircrafts specially chartered for the new recruits. During the Delhi study, all the young nurses were preparing for IELTS or CGFNS or were waiting for a call after interviews by Gulf hospitals. Once again, their individual strategy does not imply following a solitary path. The all-women networks play the most vital part in spreading information and appearing for selection tests, without the sense of professional competition taking priority in their interactions. See for instance:

"It is a colleague from the hospital who first saw the recruitment announcement and who told it to all the girls. [The Gulf recruiters] had rented a conference room in a hotel for a day and we had to come with our C.V. I went there with three other nurses and by chance I met two other girls there who were in the same nursing school as mine in Tamil Nadu ... We had to sit for some tests. There were technical questions and they were also checking our level of English. Four out of us passed successfully and we left together three months later" (Beejee, 26 years, working in a government hospital in Muscat, after two years of experience as staff nurse in a Mumbai hospital).

\section{iii. The Step towards Gulf}

The young women who leave for the countries of the Persian Gulf today know, more or less, the social and professional conditions that await them there. More than thirty years of migration from Kerala to these countries give them enough information in bits and pieces from various nurses' stories. 
It is striking that there exists very little gap between the real life that they experience in the Gulf and the descriptions of it by the nurses -migrant and former migrants - about their lives and work in those countries, as was evident from M. Percot's observation during fieldwork in the Emirates and Oman. While people say in Kerala in a witty fashion that 'never ask a 'Gulfie'10 what their job is in the Gulf but only ask how much they earn' mischievously meaning that the migrants are ready to do any work which they are unwilling to do in Kerala. However, this does not seem to be applicable to nurses, as it is known to everyone that they do the work for which they are trained, unlike the cases of many men migrants. The prejudices that follow them are of another nature, pertaining directly to their status as women migrating alone. A Christian taxi driver in the town of Kottayam to whom M. Percot explained a little bit about her research made this comment:

"One wonders what they do once their job as nurses is over [in the evenings]. Because they are living alone there, so it is easy for them to earn more by wandering in the streets, if you see what I mean!"

One may also note that during a seminar where M. Percot spoke of her research on migrant nurses, most of the questions of the students were about the sexual harassment that migrant nurses were experiencing in the Gulf: there seems to be an exaggerated version of this experience circulating around neglecting all other aspects of their life and work. This in a sense reflects the association of nursing with the sexuality of women who practise it. The prejudice is still there for all to see!

First generation migrants - who migrated during the seventies and early eighties - illustrate a predominantly austere life in the Gulf countries. Their lives were strictly limited within the four walls of the hospitals, their lodging being arranged within the same compound. Almost all the first migrants were married and most of them were mothers at the time of their migration. Notwithstanding their responsibilities they all migrated as single women leaving their children in the care of their mother-in-laws. At first all of them imagined migration as a short-time event of two or three years, when they accumulated some easy cash and savings which would raise the 
standard of life of their family in no time. During those times, nurses did not choose their profession thinking of the chances of migration; rather the unforeseen opportunities in the Gulf hospitals literally came knocking at their doors. Of course, it was not expected of migrant nurses to help the emigration of other family members at this stage, and parents and in-laws were only eager for the extra money that was to come their way from the Gulf. But many of these nurses were pushed, by husbands as well as inlaws, to renew their contracts and work there, even against their own will. They complained of the emotional difficulty of staying away from their children and carrying on in places where there was no social life, except the company of other nurses from Kerala and the Philippines. Apart from the monotonous social life they experienced, work life offered its own problems accentuated by the perceived lack of a culture of the modern hospital system for patients in the Gulf at that time, unlike in India where they worked earlier. They also remembered the short spells of happy get togethers with family members when they visited Kerala during vacation, small parties enjoyed along with their more outgoing Filipino colleagues or the prayer meetings with fellow Christian nurses. Their memories of that period, however, are dominated by the boring days, longing for letters from home, waiting for the next vacation and the end of work contract with the hospital.

It is only during middle of the 1980s and in the wake of the Keralite mass emigration to the countries of the Persian Gulf that nurses started occupying a pivotal role in the phenomenon of family migration, starting with their spouse. The face of nurse migration changed after that. More and more of them began living with their husbands and in the case of those who had sufficient income and a job for their spouse in the same city, children were brought to stay with them. With all these developments, a sizeable diasporic Malayali social life came to exist in cities like Dubai, Muscat and Kuwait. This social life offered all the comforts and opportunities for rediscovering friendships among the migrant Malayali population in the new place, to go shopping in the Kerala stores newly established there, to go to churches, to celebrate traditional festivals and to see Indian movies. These provided more avenues for single women nurses living in hostels to meet their compatriots. In 1994, a study shows that as many as 1.3 million, 
out of about 4 million Indians working in the Gulf, were Keralites (Zachariah et al 2002: 17). The size of this diaspora grew to 1.8 million in ten years (Zachariah et al 2004: 12), though in general there was a slow down of growth in employment opportunities due to the sluggish nature of growth in infrastructure and construction activities in the Gulf region. Indeed, Keralites are establishing themselves in the Gulf region, despite the legal requirement of a 'kafil' or an Arab sponsor to support the emigration of a foreigner (Battegay 2002:113). This restrictive clause did not prevent a group of entrepreneurs from Kerala in developing business in construction and services (Venier 2003). It appears that notwithstanding the norms in the countries of the Gulf that strictly separate the immigrants from the nationals and make the granting of citizenship impossible for the former, there are increasing signs of flexibility ${ }^{11}$ as, for example, seen in the Emirate of Ajman where it is possible for the foreigners to buy land for business purposes and even homes near their business venues since 2005. The logic of segregation of the foreigners remains undoubtedly in force, but in some way it only reinforces the logic of diaspora. The Keralite population in the Gulf has grown in confidence in their own proven ability to exist and even prosper. Some of them could lay claim to the fact that they had 'appropriated' some space in favourable ways: Dubai and Muscat, for instance, are truly Kerala metropolises. Airline schedules show a larger number of flights from Kerala to various cities of the Gulf than any other Indian cities.

For the numerous Indian men who wish to cross the Arabian Sea, a spouse who is a nurse is a trump card. For those who do not have any direct means to get employed in the Gulf, having a working wife in the Gulf provides the easy way out to get the visa. In the case of those who cannot get work in the Gulf, business opportunities can be explored. A nurse who works in a government hospital can get loans for the husband to start a small business enterprise. Whatever amount earned by the husband makes the stay in the Gulf comfortable and allows for saving. One finds, after observing the development of Kerala community in the Gulf, that there have been changes in the way they perceive their stay in the Gulf. They no longer think of their stay in the Gulf as short-term, rather their stay lasts for an extended period, and contracts are renewed for longer periods. Many women speak positively of their lives as they lead their lives more happily 
than in Kerala or elsewhere in India. For the majority among them, there are two advantages. First of all, to be away from family (in-laws, particularly) and the social pressure of their original community sphere is admittedly a boon in itself. Interestingly, they appreciate the cosmopolitan nature of the Gulf cities for their anonymity and freedom, not so much for their participation in the Gulf social fabric:

"Here, we don't do things only because we have to ... Most of the time, with my husband, we go shopping in Ruwi ${ }^{12}$, but sometimes we go to a big modern mall and it is another world ... For the church too, we can choose: for the mass, I go to St-Paul-and-St-Pierre church, but otherwise, I rather choose the prayer group we organize with other nurses of my hospital which is conducted by a preacher" (Pax, 36 years).

"In Kerala, if a married woman doesn't wear a sari, they will speak badly about her. But here, I only wear churidars and nobody really cares. One can live in a more modern way. We don't have the same relations with people because we don't have to take care so much about bad judgments or gossiping" (Maryam, 32 years).

"Every week-end, we meet with some friends- couples and we have fun together. If all the family was there, it would not be the same. In Kerala, family comes first especially for a woman. There, men can meet outside with friends but women stay at home” (Jenny, 32 years).

There remain, nevertheless, complaints and anxieties regarding statutes applicable to foreigners, notably Indians:

"They [the locals] are racist with Indian people, they consider us like slaves just good enough to work hard though they are totally uneducated and are not able to do things by themselves. There are the foreigners who built everything 
here and who still manage everything. If they were not lucky

to get oil, they still would be walking behind their camels!"

remarks Rosy, a 35 year old lady who lives in Muscat with her spouse and children.

Repeatedly, the same issues were raised. One notes the contempt being systematically expressed towards the native Arabs who are designated by the word 'Bedouins'. These remind one of the ways in which the relation between the migrants and the nationals are defined in the present context where one is seen as directly at the mercy of the other. Still there remains the fact that administratively and legally they are dependent on these locals whose power is loathed. As we mentioned earlier, the contract can be for one year and can be extended to three years or more. Going by nurses' own perspective, the quality of their work is not the sole criterion deciding the renewal of the contract ${ }^{13}$ but a pregnancy, a moody boss who takes offense easily or another one with a political position favouring nurses with another nationality or religion and so on. During the fieldwork in the Gulf, we met women who were working there for more than twenty years, but there was only one case when a woman was forced to resign during her initial contract for two years due to her pregnancy. All the same, the sense of precariousness remains very strong. It is obviously linked to the legislations concerning immigrants and their non-integration in the local society which incidentally is not desired by either of the two (Longva 1997).

Thus except the nurses who arrived in the 1970s, no other immigrant nurse can speak in Arabic - along with English that they speak at their workplaces - and only two of the interviewees have ever entered the home of a local family at the time of a marriage. There are no possibilities of registration as citizens nor any possibility of owning a house, adult children cannot get visas and complete dependence on 'kafils' to get visas for spouses of the immigrants and so on, restrict the possibility of assimilation with the local population. Paradoxically, the very reasons that helped the development of Kerala diaspora in the Gulf have caused nurses to think of an alternative - migrating elsewhere or returning to Kerala — rather than settling down here. This decision of theirs, as women, is primarily influenced by their experience of pregnancy and maternity - 'part-time motherhood' as they call it. Theoretically nothing prevents them to have their children 
around them if their spouses joined them as migrants (only men can get family visa in the Gulf countries), especially because the family income of two would be sufficient and Indian schools opened at various places in the Gulf ensure that their children will be getting the same education as that of their home country. Nevertheless practical difficulties to this family reunion exist in the forms of the absence of any childcare facilities and the unaffordable rents of bigger, private apartments. Moreover children's educational expenditure reduces the amount of money they can save. Many nurses, therefore, leave their children mostly in the care of their in-laws, at least for long periods. Thus, after weighing the pros and cons of their stay with them, parents often choose their children to stay on either side of the Arabian Sea. Yet, they are sure to be in Kerala by adolescence. The interviewees were unanimous that their children's college education will be better in Kerala and that keeping the contact with their country of origin is believed to be good. When these women decide to save more money and console themselves that the price of their ambition is the separation from their children, they report themselves to be emotionally suffering a great deal. We will see later in the paper that these women make much effort to lessen the negative consequences of the physical distance. They mourn the fact that they are involved in an intricate relation with their in-laws who look after their children. They oscillate between feelings of indebtedness on the one hand and jealousy on the other towards their in-laws (sister-inlaw and mother-in-law) who take care of their children and thus are the immediate recipients of their affection.

Nurses in the study deconstructed the monolithic and uniform image which the Persian Gulf has come to assume in the minds of the researchers. The diverse practices in the cultural, political and religious spheres of the region present themselves in nurses' discussion of their experiences. There exists, finally, a hierarchy of countries based on the migrants' perception of development, quality of life and the perceived salaries: the Emirates (especially Dubai), Kuwait, Oman (Muscat, to be precise), Bahrain and Qatar are at the top of the list. Last come Yemen, considered being 'not developed', and Saudi Arabia. Nurses are in remarkable agreement on the last one: "It is jail". They compare and contrast the freedom in India and Saudi Arabia. They are reported to be enjoying comparatively more freedom in other 
countries of the Gulf and are especially vocal on the restrictions in Saudi Arabia. For most of them, their gender and religious identities - as women and Christians - inform their response to the challenges in store in Saudi Arabia. Their evaluation of the quality of their freedom in India in terms of physical mobility and religious freedom is seen in sharp contrast with the situation in Saudi Arabia. When they stay as unmarried women, they are strictly within the hospital compounds, with their mobility highly controlled and restricted. They can move out of the hospital premises only in groups, veiled and in scheduled intervals accompanied by a security guard. They narrate the mental harassment ${ }^{14}$ over the delay while shopping in a boutique, over the conversation with a man colleague or compatriot inside the hospital and the difficulties of meeting a friend or a family member who is working in Saudi Arabia. The ban on all kinds of practices of religion other than Islam is also resented strongly and equally tough is the feeling of determination they shared in singing religious songs and praying, of course in low volume. They made efforts to hide the small crucifix worn on their necks and successfully went beyond the search in the airports for bible and religious tapes. They say that life in Saudi, even when they are living in families is difficult and these problems are not specific only to nurse migrants ${ }^{15}$. Dina, 36 years, who lived in Jeddah for 10 years, points out:

"Can you imagine having to wait for your husband in order to do anything? You can't go by yourself to pick up the children at school, it is not even possible to go to the next door shop to buy something you forgot to prepare a meal; you can't go visiting a sick friend ... It is impossible to have a real social life here since there is no freedom."

Nevertheless, the global power scenario and existence of hierarchy in the perception of the citizens based on economic power and position of countries do seem to matter in the treatment of immigrants. Keralite migrants also report the discrimination between different types of migrants: «Americans, they are allowed to have a church. Why is it forbidden for us?» and there is also the way they feel a tension in the air when that have to deal with the local population: 
"My husband got involved in a small car accident with a Saudi. The latter had crossed a red traffic light, but he didn't want to admit it. And he was the one the police trusted. We could have gone to court, but why? Here, Indians have no chance to win!" (Lethika, 43 years).

Nurses, therefore, look for ways to escape Saudi Arabia, proving once again that economic reasons alone cannot explain migrant behaviour. It is thus frequent that after a first contract of two or three years they return to India and find a contract in a more desirable country in the Gulf or in the West.

\section{iv. Return and Set off Again for Farther Destinations?}

Their ties with Kerala remains strong whatever their family situation and the period they work in the Gulf. While the poor and unqualified people among Malayalis cannot afford a visit to Kerala often for years ${ }^{16}$, nurses come back to Kerala every year. Their contract enables them to have a month vacation and an air ticket to Kerala ${ }^{17}$. Many of them choose to return during Christmas or Easter in order to celebrate them with the family. Since they can afford a trip to Kerala, nurses visit their families in Kerala on other occasions like death or illness in the family and marriages of relatives. Motherhood and pregnancy are major reasons for women to return to Kerala, to their parents' house as per the tradition, since most choose not to deliver in the Gulf even if they have healthcare facilities. The contracts they enter into do not give them any maternity leave but allow them to avail unpaid leave for two or three months. They often leave their new born babies with in-laws in Kerala, knowing well the practical difficulties of caring for the children in the Gulf. From then on, ties with Kerala tighten more than ever before:

"Before [the child birth], with my husband, we used to phone three to four times a month. But now that there is the baby, I call almost daily because I want him to hear his mother's voice so that I don't become a stranger for him. And the others [i.e. the in-laws] give me news from 
everybody. We know everything about what happens there"

(Beemole, 30 years, mother of an eight month old baby).

But in a manner that could appear paradoxical, the question of final return to Kerala becomes less and less certain as their visits to Kerala become more frequent. Older nurses who were interviewed, emigrated with this short term perspective in mind whether their husbands follow them or not to the Gulf. The objectives of their migration were clear and well-defined: saving enough to construct a house in Kerala, noticeably almost always near the house of in-laws, save enough for the higher education of their children and/or for the small business that the husband is going to start. Once they save sufficiently for these, they return to Kerala and stop working ${ }^{18}$ which marks clearly upward mobility in the social hierarchy. To fulfill this aim of sufficient saving, several years of stay is essential - seven years in a single or several stints of migration, on an average for women whom we met in Kerala. Just as there are several cases of success, there are setbacks also. Mostly it is the husband's failed business - being an inexperienced entrepreneur struggling to manage the small business or the unsuspected victim of a fraudulent entrepreneurial partnership (as the exmigrants describe it), a serious accident or illness in the family which involved unforeseen expenditure or a divorce resulting in unanticipated expense for resettling and so on. At the same time, most of these ex-migrants — including those who are 'successful' - find it difficult to readjust to the social life of Kerala, especially within the realms of extended family. They think of their society as too provincial in attitude and interfering, as interested in gossips, and lacking in entertainment opportunities. Their disenchantment with Kerala goes to the extent of expressing resentment over the humid climate! Clearly once they are confined to the family having left their job, which in fact was an objective in itself, they find themselves confronted by a challenging situation. They feel strongly that they have contributed to the family in no small measure and are the ones who bore the brunt of migration and related hardships, they are uncomfortable with the traditional roles of daughter-in-law in the domestic space, submitting to its hierarchy as well as logic of redistribution and allocation of resources. This ambivalent and complex picture of processes 
and dynamics of return to Kerala is more evident in the case of the older nurses in comparison to the younger ones. The latter are very well aware of the consequences of their migratory steps and are not ready to reduce themselves merely to the status of financiers of their families.

"I don't want to work all my life to pay for a full set of uncles, aunts and cousins, to pay for the dowry of this one or the studies of another one" explains Alice, 32 years, who is preparing herself to leave Dubai where she worked for the last six years with her husband and two children, to go to the US where she just got a contract.

Objectively speaking, migration offers a chance or solution, in a comparative sense, to these women who do not have the means or ways to change the prevailing strict social norms that govern family lives in Kerala. This compels us to consider the choices of nursing by young women as decisions beyond the realm of economic necessity. Opportunities to earn better through migration encourage women to opt for nursing. And of course, this instrumentalist approach to nursing by younger women adds to the fear of many puritans who complain of nursing having lost its true spirit of 'vocation' or 'calling'.

Not to talk about the interest young men show in these young nurses! Nurses know their potential to win over a more qualified husband than what the older nurses could manage fifteen or twenty years ago, apart from enjoying a different passage of life if they live within a traditional family. Matrimony and related processes are well-knit in their 'life-plan,' which was narrated to the researchers, where migrations form inevitable episodes. The marriages remain certainly arranged by families, something that women don't try -or are not even willing — to challenge, but the young couples show an explicit individualistic orientation vis-à-vis their families which expresses itself in their reluctance to share their fruits of labour with other members in the extended family.

They are tilted in favour of nuclear families higher up in the social ladder and therefore want to save as much as possible. And these women seem to be acting as the watchdogs of this strategy. 
"My husband is a generous man. When his family asks [for something or some money], he will always say OK. But I always repeat to him that our priorities are our children. One can't give just like that! ... I never said a word when it is to help mother or father. Parents must get respect and it is normal to help them, but you have to be careful because savings are easily spent and if we don't want to loose our goal, we have to be very serious"

says Pax, 36 years, who works in Muscat, has her two children with her and wishes to migrate to England or Ireland with her immediate family. As several other nurses explicitly stated, she asserts her rights to have access to bank accounts and to have her say in money management. As in the case of many of her colleagues, she jokes about her 'touchy' husband when it comes to his spouse earning more than him. This is described as sensitivity of the husband that shows up frequently when he speaks to others. Indeed, husbands of many of the nurses talk about their wives' salaries as 'savings' whereas their own are described as the means of support of the family. It is important here to point out that it's actually the women who are proactive with regard to the destiny of their families even if that does not necessitate any revolutionary change in the familial roles.

In fact the migratory plans do not end with the Gulf, but rather extends beyond that ever since shortage in the supply of nurses led to mass recruitment of nurses in different western countries ${ }^{19}$. The dream of a 'Green Card' is within the reach of nurses as testified by many advertising panels in Kerala that lure women with the information of various courses and diplomas, Statue of Liberty or the US flag with 50 stars and 13 stripes significantly forming the background. Kerala nurses, indeed, were hired in the US as early as the end of 1960s (George 2005) or in Great Britain. But they, as in the case of the Kerala migrants in general, were not conspicuously large in number in western countries (Zacharia et al 2004:12). But over the last few years, nurses' movement to the western countries has increased by tens of thousands or even by hundreds of thousands (Kingma 2005: 25). The West is not a fantasy place for nurses but is a realistically chosen place of work. And unlike the Gulf, they think of it as a desirable social space to settle down: 
"Here [in the Gulf] we work and save with the idea of coming back home one day to live, at last, our life. But if we can go to the West, it is different, because one can really settle down if one wishes. Children may grow up there, go to good universities, it is possible to get citizenship, to buy a house, to build a new life"

specifies Janet, 37 years, who works in Muscat and is preparing for various tests that enable her to immigrate to the US. She also learns French from the French Cultural Centre in Oman that would earn her some points in her eventual migration to Canada.

Despite this preference for the West, the whole process of decision on emigration to this destination is heavily bogged down by pragmatic considerations which are based on the experiences of the majority of NRIs (Non-Resident Indians) working in the western countries. Nurses are well aware of this migration as a rupture, at least as a long distance with the country of their origin. They also pertinently understand the possibility of their children being grown up as 'aliens' to their own culture and finally not returning to India, as experiences had shown in many cases. All the more so as the children will not be sent to school where Malayalam is taught and this is a particularly sensitive issue for many nurses working in the Gulf $^{20}$. They evoke the question of cultural assimilation or integration of migrant communities that is not possible in the Gulf. Segregation of immigrants and natives in the countries of the Gulf is qualitatively different from that in the West but on the other hand the presence of Keralites is not in the same proportion to speak about diaspora in the same fashion. Professionally too, nurses do not add up much in number in the West and are not comparable to their situation in the Gulf. Some of the nurses who were interviewed in the Gulf and later moved towards the US and Ireland confirm this:

"Everything is beautiful here, wrote Dina who is now working in a small city in Connecticut, and my colleagues are nice ... We are only three women from Kerala. We decided to share the same kitchen in the hostel ... like that we can prepare food for each other. Before, I was sharing the kitchen with Filipino girls. They are very joyful and 
nice women, but I didn't like the smell of their food. That is normal, one always prefers the smell of one's own food ... Within two months, Nirmal and Joel [her husband who was still working in Abu Dhabi and his two years old son who was living with the in-laws in Kerala respectively] will come to join me. I need to find an apartment. They told me at the hospital that they will help me, but I don't know what will happen because rent is very high here".

Benny who is now living in Dublin points out: "Our children are the only Indians in their school, ... and they like to be here. This is also because they are happy to live with their father and me ... I have a few colleagues from Kerala and one from Punjab. We keep on saying that we should invite each other at home but still didn't find the time to do so".

George (2005) illustrates that the Kerala immigrants in the US recreate the cultural distinctiveness of Kerala around the churches, as in the case of California. On the one hand nurses make critical comparisons and contrasts between the West and the Gulf region in terms of integration of immigrants and freedom and talks about the lack of policies of integration in the latter. But on the other hand, a melting pot model is not seen as desirable either. Integration is seen as good when it is on their own terms and is nonthreatening to their cultural identities and when the freedom to keep their cultural identity intact in the new space is available.

At the same time, nurses are impatient to cross over to the West. Social pressure irrefutably is part of the game of this emigration to the West. It is difficult to cross the borders of the western nations and as a result doing what is perceived as success, is a privilege in itself. Not seizing the first opportunity to migrate to the West is seen as foolishness in India in general and Kerala in particular which has familiarized itself with the culture of emigration. Nurses are acutely aware that while the salary in the West is higher, three to four times greater than in the Gulf, life is much more expensive there. Their chances to save, therefore, are less. When, for all the above reasons, they leave for the western country from the Gulf, they 
are rather choosing a lifestyle. Well organized public life, respect for the law, affluence, cosmopolitanism and famous universities with high academic standards along with the impression that the West is the happening place (contrary to Kerala where life just goes on) are the reasons they give to explain their preference. Here they plan for long-term professional arrangements and for a future with husband and children with them within the laws of the host countries, aiming to apply for citizenship, all the while keeping themselves away from the immediate family supervision and interference. There is a long route towards this end, which necessitates preparation for tests and examinations for a long time. It is no secret that most of these young women would like to leave directly for western countries if their family succeeds arranging for sufficient funds for it, but so far, most of these young women find their own ways to emigrate to a Gulf country, accumulate experience as a staff nurse in a well-equipped hospital, earn for their dowry and marry and then start preparation for IELTS and CGFNS. Some of them, after some years in the Gulf, take advantage of the period of their maternity in Kerala to prepare for these examinations ${ }^{21}$.

As in the case of the migration within India and to the Gulf, female networks play important roles in disseminating and spreading information on appointments in the West, on the best coaching centres for the examinations and on recruiting agents. However mass recruitment programmes, unlike to the Gulf, do not exist and selection procedures are deemed as much more difficult than towards the Gulf. Nevertheless, their confidence in planning their departure is palpable:

"Why should I be afraid? I worked for two years in Mumbai, two years in a rural hospital in Saoudia, five years in Abu Dhabi. I know what is a foreign country ... I have been back [in Kerala] for two years, but what am I doing here? Nothing. My children are still young and I think that it is better to leave now" explains Cecilia, 35 years, who is aiming to migrate to Canada and she adds-like many other nurses"Malayalis are everywhere" 


\section{Summing Up}

In a coaching centre for IELTS and CGFNS at Kottayam, Kerala an atlas of the world was hanging from the wall showing the various potential destinations for nurses, on the model of airline maps. Thin red threads were joining Kottayam to New York, London, Montréal, Canberra and so on. This is symbolic of the 'simple' fact that the world is open for the nurses from Kerala. Families in Kerala seem to very well understand this and encourage their girls to choose this profession. Thus women are entering nursing profession, cutting across castes and the financial standing of the families- like the Nair girl whose father is serving in a big temple at Thiruvananthapuram or the Ezhava girl whose father is an autorickshaw driver who is financing the nursing education of her two younger sisters with her salary from the Gulf. In-laws also seize the opportunity to have a daughter-in-law who is a migrant or potential migrant and young nurses are better qualified than others for that. This clearly denotes an improvement in the status of nurses in certain arenas of society.

Young nurses who migrate to the Gulf keep their ties with Kerala very strong. Their families and need for childcare make it necessary to have constant exchanges with members of immediate and even extended family. Exchange of gifts, sending money, telephone calls etc make their relationships thrive. However, this solidness of contact slackens once they migrate to the West. The nuclear family is systematically nurtured and visits and gifts with other members of the wider family become less and less frequent. This migratory movement that started at the time of the studies of these nurses does not stop but keeps growing in different directions. It is not just a matter of kilometers and the cost of their tickets but rather a way of life. Since the first step - to the school of nursing from the residence of their parents - through the various steps of migration to Indian cities and the Gulf and the West and sometimes back to Kerala, they perceive it as one step towards more freedom.

Dominant understanding of the West as the ultimate destination that is currently in circulation overlooks the processes of migration that are complex and happen through routes not always linear as in the case of these nurses. Step-by-step process of migration of the nurses, as narrated in 
this paper, succinctly puts the nuanced nature of migration processes to the fore. Migration of these nurses unveils acts of 'multiple movers', with highly complicated, individual initiatives, which to outside observers appear uniform and homogeneous. The time tested 'embeddedness of the migrants in family and household strategies' (Harzig 2001:23) is evident in the case of nurses too. 'Meso-level' decision-making linking individual experiences with the structural factors at the economic, social and political best explains the migratory choices of nurses.

Voices of nurses contain not any simple understanding of their experiences but they leave the researchers with some issues for further probing. Are their migration liberating them from the patrifocal roots or are they only ways of reconstructing the old traditions in the new contexts? Is there any alternative to rebuilding the 'tools of patrifocal controls' for the family to remain as a single unit, considering the strong ideological support of family as an institution in the larger society?

\section{Endnotes:}

${ }^{1}$ This paper took shape in September-November 2005 in the Laboratoire d'Anthropologie Urbaine (UPR34 CNRS), France during the ICSSR-MSH research visit of Sreelekha Nair. We have taken care to retain the rich data gathered by the two researchers in their fields. Original version of this paper in French Comment s'ouvrir les frontieres du monde: la migration des infirmieres indiennes is accepted for publication in Veronique Dupont, Frederic Landy (eds.), Circulation et territoire dans le monde indien contemporain, coll. Purushartha, Editions de l'EHESS, Paris, 2007.

[Marie Percot, Laboratoire d'Anthropologie Urbaine (UPR34 CNRS), Paris, France mpercot@aol.com; Sreelekha Nair, CWDS, New Delhi, India, writetosree@gmail.com.]

2 See Thapan, Transnational Migration and Politics of Identity, pp. 11-12, 2005.

${ }^{3}$ Women leave their families, mainly from the countries of Asian continent (Philippines, Sri Lanka, Indonesia...), for working as domestic helps, babysitters, nursing aids for aged people etc. in rich countries where these jobs are felt as unattractive to the native population (Abella et Manolo 1995; Battistella 2001). So 
far better qualified among these women migrants are basically nurses and many of them are Indians. Indian doctors also have migrated to the United States and the United Kingdom but their migration is limited in volume and cannot be called a mass migration (see for instance, Raghuram, 2004).

${ }^{4}$ A Malayali is the inhabitant of Kerala while the language is called Malayalam.

${ }^{5}$ Study on Malayali nurses in the Gulf was carried out by M.Percot and the second study by Sreelekha Nair.

${ }^{6}$ Maitrayee Chaudhuri's article on fieldwork among Asian Indian Americans in the United States titled 'Among My Own in Another Culture: Meeting the Asian Indian Americans' explores the process of mutual interpretation of the anthropologist and the 'subjects' and discusses how the 'Indianness' is understood by both the parties.

${ }^{7}$ GNM course (Diploma in Nursing and Midwifery) requires three years of training while B.Sc. in nursing requires four years and, there are other less intensive courses like ANM (Auxiliary Nurse-Midwife) course which qualify the trainees to be assistants to nurses rather than becoming full-fledged nurses.

${ }^{8}$ She was finalizing her procedures of migration to Ireland during the interview while trying also for other places in Europe. She started working as a staff nurse in Ireland after resigning her job as a permanent staff nurse in a Delhi government hospital, by the time the researcher finished the interviews for the study.

${ }^{9}$ IELTS: International English Language Testing System; CGFNS: Commission on Graduates of Foreign Nursing Schools (a compulsory test to work in the USA).

${ }^{10}$ Term sometimes used to denote a person who works or worked in the Gulf.

${ }^{11}$ There has not been any major change in the immigration policies of the Persian Gulf countries during the last three decades. The only remarkable change is in terms of the right granted to foreign businessmen (a lot of them are Indian) to buy land (and become real owner) in order to build factories in UAE. With this right comes also the right to build a house on this land. Of course, it has no consequence for ordinary migrant workers (who are not allowed, till now, to invest in a house). 
Otherwise, changes have been minor. Interestingly with all the restrictions that they resent, number of Indian workers has increased many folds (see For example Zachariah et al. 2004).

${ }^{12}$ An Indian neighbourhood (mostly Malayali) of Muscat

${ }^{13}$ Renewal of contract is described by nurses as a routine thing. It is a smooth process in government hospitals but there seems to exist some anxiety when it comes to private hospitals, especially small ones. Generally nurses know in advance whether there is going to be a problem. So they apply for jobs in other hospitals. Periods of contract differs from country to country in the Gulf.

${ }^{14}$ Warnings, memos or even deduction of salary.

${ }^{15}$ We agree with Dr. Sabiha Hussain that gender, irrespective of religion and nationality is fundamental in immigrant women's experiences anywhere in the world. Nevertheless as the largest segment of single-women worker migrant population, nurses seem to perceive that their nationality and religion play important roles in forming the responses of the locals.

${ }^{16}$ There is no statistics, but it seems that unskilled people never visit their home for 5 to 7 years. It is reported that there is also a large number of suicides among these unskilled workers who are not able to repay the debt of going to the Gulf and are no way in a position to save money to send to their family.

${ }^{17}$ We came across only one case where this clause was not respected: three girls, who had left for the same hospital in Saudi Arabia, told us that all the Indian nurses of their hospital had been on strike to acquire their right to vacation specified in their contract. All three came back at the end of their three years of contract and were searching for a contract in other countries.

${ }^{18}$ Generally return migrants decide to work only when they find a post of nursing supervisor or a teacher in a nursing college or else find a post in government hospital where wages are high. Or else they decide to quit work altogether. It is interesting to note that the hospitals of Kerala, to be able to keep experienced nurses, allow fifteen to twenty years of unpaid leave (in periods of five years maximum). Among 
the nurses interviewed in Delhi, there are a few who had returned from the Gulf but are still working as staff nurse in private hospitals.

${ }^{19}$ Mainly the United States, Great Britain, Ireland, Canada, New Zealand, Canada, Australia and, to a lesser extent, Germany, Switzerland and Italy.

${ }^{20}$ A number of Indian schools in the Gulf teach Malayalam.

${ }^{21}$ We met a large number of women ex-migrants or those who are between two steps of migration preparing for these tests in coaching centres which are on the rise in Kerala. They also find such schools in the main metropolises of the countries of Gulf. 


\section{References}

Abella M., Manolo I. (1995) "Asian labour migration: past, present and future”, ASEAN Economic Bulletin, 12(2): 125-138.

Aravamudan,Gita(1976) "Nurses and Nuns from Kerala", in Devaki Jain Ed. Indian Women, New Delhi: Government of India: 261-270.

Battegay, Alain (2002) « Postface: l'ordre urbain de Dubaï, ville-émirat du Golfe arabo-persique ", Monde Arabe Contemporain, Cahiers de Recherche du GREMMO. Numéro spécial, Lyon: 107-16.

Battistella G. (2001) « Migration 2000 in Asia: a year in review », Asian Migrant, 14(1): 5-20.

Chaudhuri, Maitrayee (1998) Among My Own in Another Culture: Meeting The Asian Indian Americans in Meenakshi Thapan (ed.) Anthropological Journeys reflections on fieldwork. Orient Longman, Hyderabad: 188-214.

Davison, Mariquita (1993) Philippine Nurses, Voices of Struggle and Determination. Berkeley, University of California, unpublished $\mathrm{PhD}$ Thesis.

George, Sheba M. (2000). “'Dirty Nurses' and 'Men who play: Gender and Class in Transnational Migration", in Michael Burawoy Ed., Global Ethnography: forces, connections and imaginations in a postmodern world, Berkeley: University of California Press: 144-74.

George, Sheba M. (2005) When women come first. Gender and Class in Transnational Migration. Berkeley, University of California Press.

Harzig, Christiana (2001) Women migrants as global and local agents New research strategies in gender and migration in Pamela Sharpe(ed.) Women Gender and Labour Migration, London: Routledge: 15-28. 
Jeffrey, Robin (1993) Politics, Women and well-being, How Kerala became a model, New Delhi, Oxford University Press (Paperback).

Kingma, Mireille (2005) Nurses on the Move: Migration and the Global Health Care Economy, Cornell University Press.

Longva, Ahn Nga (1997) Walls Built on Sand. Migration, Exclusion and Society in Kuwait. Oxford: Westview Press.

Mohan, N. Shantha (1985) Status of nurses in India, New Delhi, Uppal Publishing House.

Nair, Sreelekha and Madelaine Healey (2006) A Profession on the margins: Status Issues in Indian Nursing, occasional paper no. 45, Centre for Women's Development Studies, New Delhi.

Percot, Marie (2005) « Les infirmières indiennes émigrées dans le Golfe : de l'opportunité à la stratégie », in Revue Européenne des Migrations Internationales 21 (1) (Femmes, genre, migration et mobilités, sous la dir. de Christine Catarino, Mirjina Morokvasic et MarieAntoinette Hily) : 29-54.

Percot, Marie (2006) Indian Nurses in the Gulf : From Job Opportunity to Life Strategy, in Anuja Agrawal (ed.) Migrant Women and Work,, New Delhi/Thousand Oaks/London, Sage Publication : 155-176.

Percot, Marie; S. Irudaya Rajan (2007) Female Emigration from India: Case Study of Nurses, Economic and Political Weekly, Volume XLII, January 27- February 2: 318-25.

Raghuram, Parvati (2004) The difference that skills make : gender, family migration strategies and regulated labour market Journal of Ethnic and Migration Studies, 30 (2): 303-21. 
Srinivas M.N. (1996) Indian Anthropologists and the study of Indian Culture, Economic and Political Weekly, Vol. 3(11), March 16: 656-657.

Thapan, Meenakshi (2005) Series Introduction in Meenakshi Thapan (ed.) Transnational Migration and Politics of Identity, New Delhi, Sage Publications:09-22.

Théau, Benoît ; Venier, Philippe (2001) <<Kérala : la force de l'ambition >>, Poitiers, Orcade.

Venier, Philippe (2003) Travail dans le Golfe persique et développement au Kérala. Les migrants internationaux, des acteurs au cœur des enjeux sociaux et territoriaux. Université de Poitiers, unpublished $\mathrm{PhD}$ Thesis.

Visvanathan, Susan (1993) The Christians of Kerala. History, Belief and Ritual among the Yacoba, New Delhi, Oxford University Press.

Zachariah K.C., Kannan K.P., Rajan S.I. (2002) Kerala's Gulf connection. CDS studies on International Labour Migration from Kerala State in India, Trivandrum, Centre for Development Studies.

Zachariah, K. C., Rajan S.I. (2004). Gulf Revisited. Working paper No. 363, Trivandrum, Centre for Development Studies. 